\title{
Working Memory and Language
}

A latent variable longitudinal study

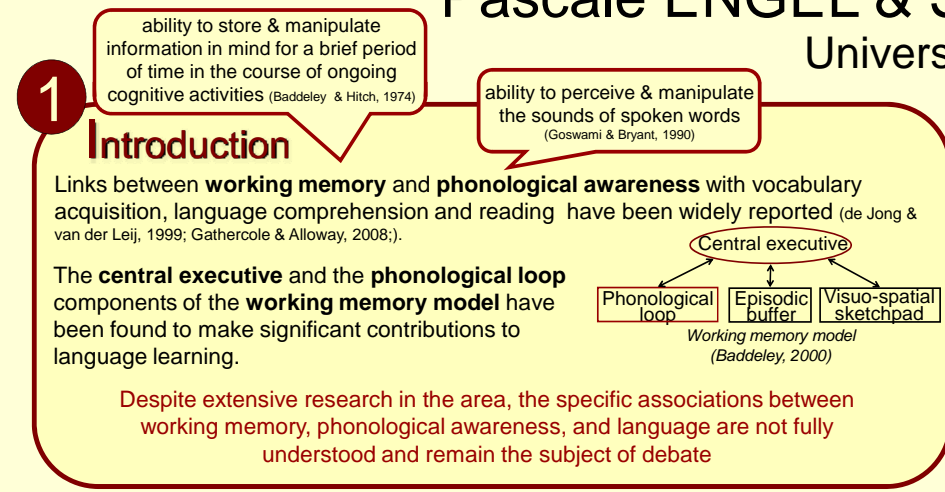

AIM

Assess working memory and phonological awareness in young children exposed to multiple languages in order to explore their relationship with developing language skills in the areas of vocabulary, comprehension, and reading.

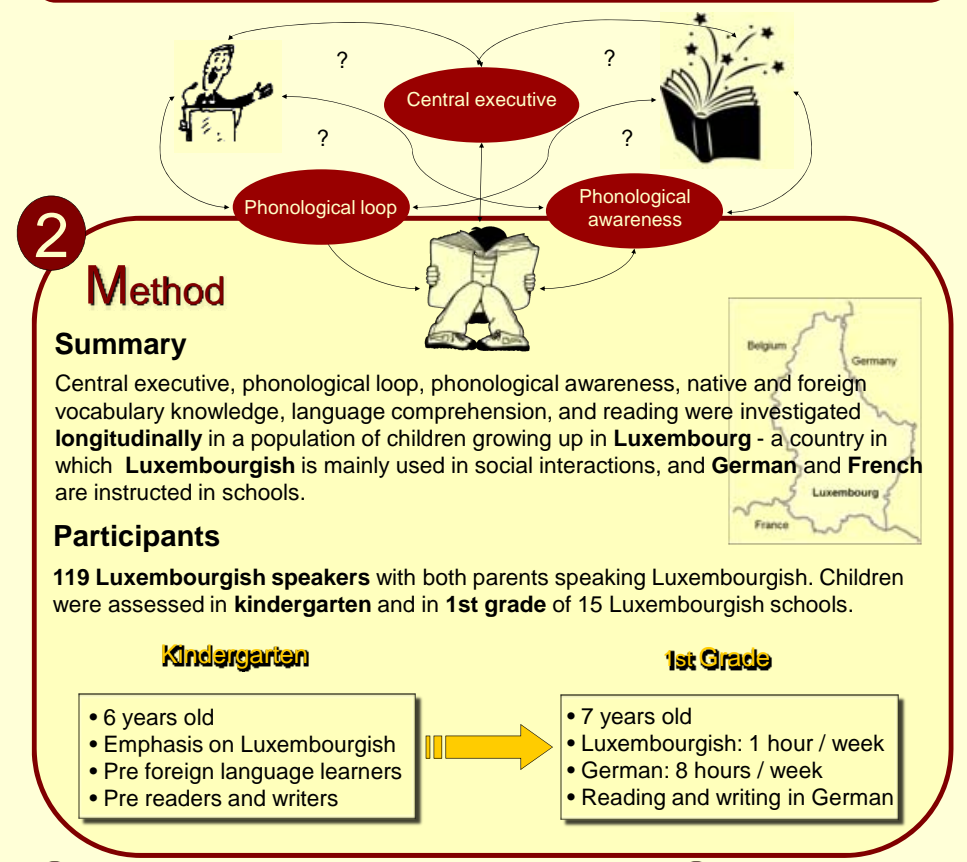

\section{3}

cos

Central executive

Phonological loop

Rhyme detection easy

Rhyme detection diff.

Alliteration

Spoonerism

Syntactic comprehension Luxembourgish German

Expressive vocabulary Luxembourgish German

Reading

Fluid intelligence Raven's matrices

Letter decision

Word detection

Single word reading

Text reading
- 7 years old

Luxembourgish: 1 hour / week - Reading and writing in Germa

Discussion The findings lend strong support to the position that the phonological loop is one of the main contributors to new word learning in both native and reciprocal relationship between phonological loop functioning and vocabulary acquisition rather than a simple one-way causal association. The phonological loop seems to exert indirect effects on language comprehension and reading via vocabulary knowledge. The central executive appears to makehighly specific contributions to reading

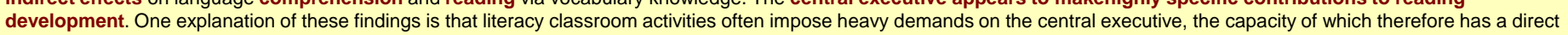

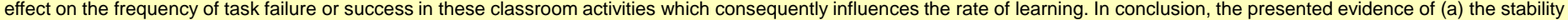
feindididual differences in young children's working memory capacity and, (b) causal relations of working memory with learning reinforces the value of early screening of working memory abilities to identify children who are at risk of poor academic progress over the coming years. 
- $\quad$ Gathercole, S. E., \& Alloway, T. P. (2008). Working memory and learning: A practical guide: Sage Press.

- $\quad$ Gathercole, S. E., Willis, C. \& Baddeley, A. D. (1992). Phonological memory and vocabulary development during the early school years: Evidence from a longitudinal study. Developmental Psychology, 28, 887-898.

- $\quad$ Goswami, U., \& Bryant, P. (1990). Phonological skills and learning to read. Hillsdale: Erlbaum.

- $\quad$ Gupta, P. (2003). Examining the relationship between word learning, nonword repetition, and immediate serial recall in adults. Quarterly Journal of Experimental Psychology Section a-Human Experimental Psychology, 56(7), 1213-1236.

Baddeley, A. D., \& Hitch, G. (1974). Working memory. In B. G. (Ed.), The psychology of learning and motivation (Vol. 8, pp. 47-90). New York: Academic Press.

Baddeley, A. D. (2000). The episodic buffer: a new component of working memory? Trends in Cognitive Sciences, 4(11), 417-423

de Jong, P. F., \& van der Leij, A. (1999). Specific contributions of phonological abilities to early reading acquisition: Results from a Dutch latent variable longitudinal study. Journal of Educational Psychology

and Aging, 91(3), 450-476. 